\title{
Reseña trabajos de grado de estudiantes de licenciatura en educación básica con énfasis en humanidades y lengua castellana
}

\section{A review. Humanities and spanish language focused basic education teaching candidates papers to opt to their bachelor's degree titles}

Patricia Arango Zuleta ${ }^{3}$

\section{Presentación}

La siguiente reseña es sobre trabajos de grado de estudiantes de Licenciatura en Educación Básica con énfasis en Humanidades y Lengua Castellana, cohorte uno, conformada por Normalistas Supriores en el Municipio de Jericó, quienes llevaron a cabo la práctica investigativa entre 2007 y 2008.

Su realización, que partió de la lectura de cada informe para identificar generalidades y particularidades, tiene dos intenciones. La primera es reconocer el empeño puesto por los docentes en profesionalización , para aproximarse a sus realidades desde otras miradas, con un sentido de interrogación y confrontación que si bien genera vaivenes, trae consigo satisfacciones; también para invitar a continuar el camino emprendido en sus realidades institucionales y convocar a atreverse, a quienes hoy, continúan el trayecto de sus vidas acompañados por esta Institución.

Docente de la Facultad de Educación de la Universidad de Medellín.

Modalidad de práctica establecida en el Manual de práctica de la Licenciatura, pertinente para sus desempeños como directivo docentes de Centros Educativos Rurales -CER- o docentes de Instituciones Educativas - IE-

3 Normalistas superiores graduados, docentes en ejercicio en los grados de básica primaria, quienes eligieron al Tecnológico de Antioquia Institución Universitaria, para proseguir la formación y titularse en Licenciatura en Educación Básica con énfasis en Humanidades y lengua Castellana.

4 Esta Licenciatura tiene 566 estudiantes en 15 municipios de diferentes subregiones de Antioquia. 
El segundo propósito al hacer una lectura crítica de los materiales logrados por esta cohorte de licenciadas y licenciados, es ofrecer a sus protagonistas una mirada externa que invita a continuar mejorando los procesos y el desempeño laboral; a quienes están en el proceso de formación en la sede y distintas subregiones, exponerles apreciaciones que pueden aportar al abordaje de sus experiencias de práctica investigativa incluida la comunicación de lo sucedido y conquistado.

Desde el punto de vista estructural y con el ánimo de agilizar la lectura de la reseña, he identificado aspectos relevantes, por afinidad o diferencia, y los he agrupado en diferentes ítems que movilizan un proceso de investigación y están presentes en el cuerpo escrito de la misma.

\begin{tabular}{|c|c|}
\hline $\begin{array}{l}\text { Nombre del } \\
\text { municipio }\end{array}$ & Jericó. \\
\hline $\begin{array}{l}\text { Programa } \\
\text { académico }\end{array}$ & Licenciatura en Educación Básica con énfasis eh Humanidades y Lengua Castellana. \\
\hline Cohorte & Primera de normalistas superiores. \\
\hline $\begin{array}{l}\text { Nombre de } \\
\text { autores }\end{array}$ & $\begin{array}{l}\text { Nancy Marcela Ruda, Sandra Patricia López González, Gloria Elena Giraldo López, Aideé } \\
\text { Ceballos, Dora Eugenia Zapata Bedoya, Claudia María Quijano Castrillón, León Darío } \\
\text { Caré Santos, Elizabeth Moncada Tangarife, Milena Marín Espinosa, Luz Dary Congote, } \\
\text { Ancízar de Jesús Martínez Marín, Gloria Alejandra Mejía Vélez, Lida Isabel Ramírez } \\
\text { Giraldo, Leonardo Calderón, Augusto Tamayo Cano, Ángela Marcela Gómez Moncada, } \\
\text { Sandra Liliana Ramírez, Paula Andrea Zapata, Paula Andrea Betancur Flórez, Gustavo } \\
\text { Adolfo Serna Gil.. }\end{array}$ \\
\hline $\begin{array}{l}\text { Tema de los } \\
\text { proyectos }\end{array}$ & $\begin{array}{l}\text { Estrategias didácticas, pedagógicas o metodológicas para promover la lectura y el } \\
\text { mejoramiento de la producción textual en estudiantes de educación básica. } \\
\text { Desarrollo de habilidades comunicativas, producción textual, comprensión de lectura. } \\
\text { El papel de la familia y los ambientes de lectura en el desarrollo de habilidades para leer y } \\
\text { escribir y en la comprensión de estudiantes de educación básica. }\end{array}$ \\
\hline Palabras claves & $\begin{array}{l}\text { - Comprensión, Estrategias didácticas, Estrategias metodológicas, Estrategias } \\
\text { pedagógicas, Lectura. } \\
\text { - Estrategia juego, Habilidades de lectura, Habilidades de escritura, Producción de textos. } \\
\text { - Ambientes de lectura, Recursos didácticos, Competencia comunicativa. }\end{array}$ \\
\hline $\begin{array}{l}\text { Fecha de las } \\
\text { investigaciones }\end{array}$ & $2007-2008$. \\
\hline $\begin{array}{l}\text { Número de } \\
\text { trabajos }\end{array}$ & Veinte (20) \\
\hline Tipo de trabajo & Trabajos de grado. \\
\hline
\end{tabular}




\begin{tabular}{|c|c|}
\hline Localización & Facultad de Educación y de Ciencias Sociales \\
\hline Antecedentes & 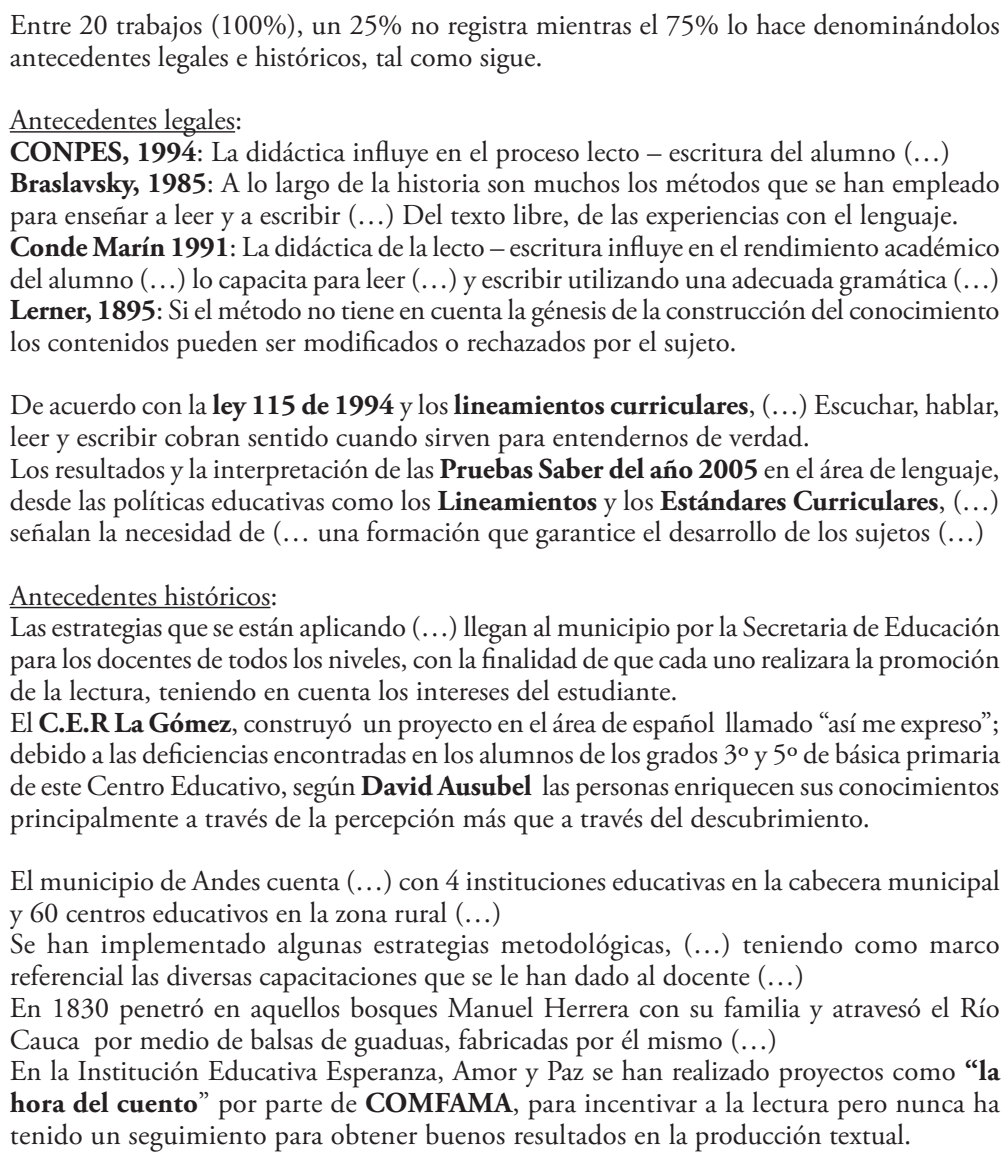 \\
\hline & $\begin{array}{l}\text { En el } 15 \% \text { ( } 3 \text { de } 20 \text { ) los trabajos tienen plasmadas entre } 5 \text { y } 14 \text { preguntas, el } 10 \% \text { (dos } \\
\text { trabajos) tiene dos preguntas y el porcentaje restante tiene una sola. Son apreciables } \\
\text { diferentes niveles de delimitación al interrogar, los agrupé en dos conjuntos que denominé } \\
\text { el de estrategias y el de búsquedas. } \\
\text { Estrategias } \\
\text { - ¿Qué estrategias pedagógicas implementar en los grados de segundo a quinto del CER La } \\
\text { - ¿Qsta para mejorar la producción textual potencializando las habilidades comunicativas? } \\
\text { - Soledad para promover la lectura y mejorar la producción textual de los estudiantes? } \\
\text { ¿Qué metodologías didáctico-pedagógicas implementar en los estudiantes del grado } \\
5^{\circ} \text { de la Institución Educativa "José Prieto Arango" del municipio de Tarso, para que } \\
\text { mejoren sus habilidades lecto-escriturales desde la comprensión y la producción, y } \\
\text { les permitan incorporarse a la comunidad de escritores y lectores en los diferentes } \\
\text { ámbitos sociales? } \\
\text { Búsquedas } \\
\text { ¿Como lograr que los estudiantes del grado cuarto del Centro Educativo Rural Moritos } \\
\text { adquieran una buena comprensión lectora? } \\
\text { ¿Cómo incrementar el gusto por la lectura y mejorar la comprensión lectora en los } \\
\text { estudiantes del grado quinto de la Institución Educativa de Jesús? } \\
\text { ¿Cómo incrementar el gusto por la lectura y mejorar la comprensión lectora de los } \\
\text { grados tercero y cuarto del Centro Educativo Rural León de Greiff? } \\
\text { ¿Cómo lograr acercamiento y buena interacción con los textos en los educandos del } \\
\text { preescolar } 2 \text { de la Institución Educativa Normal Suprior de Jericó? }\end{array}$ \\
\hline
\end{tabular}




\begin{tabular}{|c|c|}
\hline $\begin{array}{l}\text { Propósito del } \\
\text { trabajo de } \\
\text { investigación }\end{array}$ & 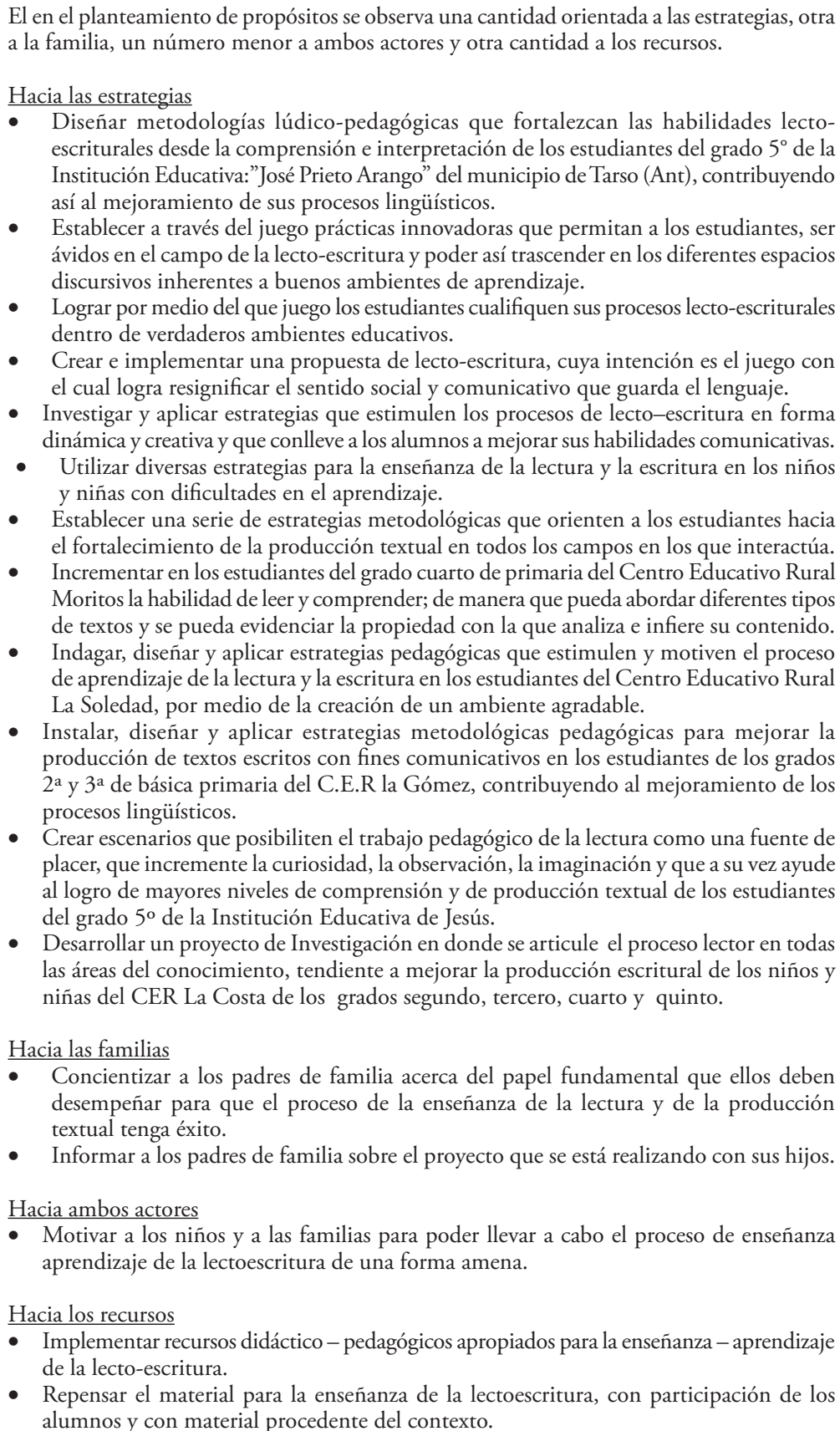 \\
\hline
\end{tabular}




\begin{tabular}{|c|c|}
\hline $\begin{array}{l}\text { Enfoque } \\
\text { metodológico }\end{array}$ & 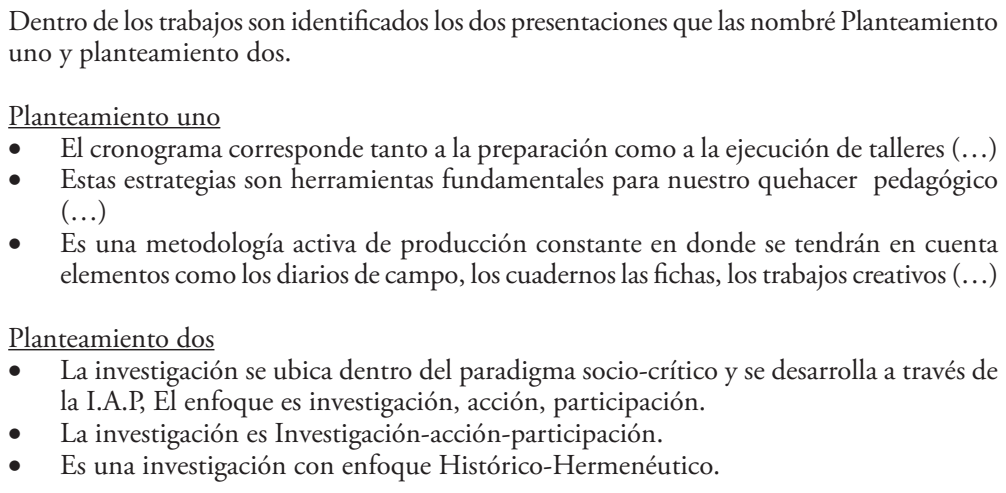 \\
\hline Conclusiones & 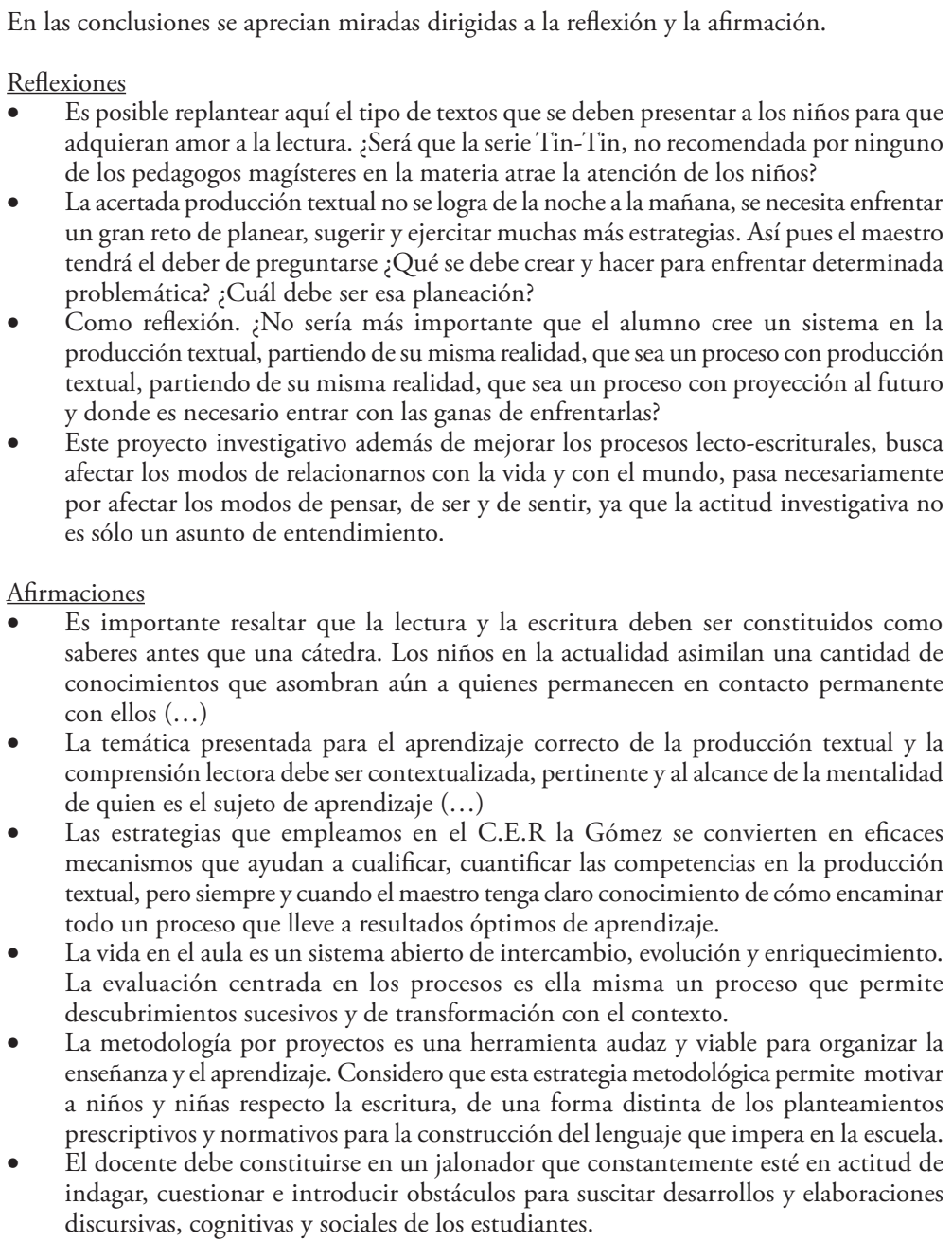 \\
\hline
\end{tabular}




\begin{tabular}{|c|c|}
\hline $\begin{array}{l}\text { Aportes de las } \\
\text { investigaciones }\end{array}$ & $\begin{array}{l}\text { - Reconocimiento de los saberes de los padres de familia para vincularlos en los procesos } \\
\text { de formación y los programas que ofrece la Institución Educativa. } \\
\text { - Contribución al aprendizaje de los estudiantes en dos perspectivas. La primera es el } \\
\text { afecto de los docentes, unido a su actualización y capacitación, la segunda es partir de } \\
\text { las vivencias, los intereses y las oportunidades de interactuar que tienen los estudiantes } \\
\text { con cuanto hay en el entorno para facilitar la expresión oral y escrita y los procesos } \\
\text { de comprensión. } \\
\text { - Concepción y apropiación del entorno del CER y donde habitan los estudiantes como } \\
\text { ambiente para el desarrollo de competencias comunicativas y de la producción de textos. } \\
\text { Dimensión de la gestión del docente a partir de las metas y propósitos de su identidad } \\
\text { y su profesión. }\end{array}$ \\
\hline Postura crítica & $\begin{array}{l}\text { En los trabajos no se aprecia el proceso seguido y los alcances varían de un autor a otro. } \\
\text { Predominan trabajos que presentan resultados sobre los que esbozan productos esperados, } \\
\text { ante lo cual surge la pregunta ¿empezaron en distintos períodos el proceso?, ¿Se presentaron } \\
\text { situaciones que afectaran la marcha de la práctica investigativa?, ¿Faltó alguna directriz para } \\
\text { que cada quien supiera hasta dónde daría cuenta de su proceso? } \\
\text { La investigación es un aprendizaje continuo en tanto el conocimiento es ascendente, en } \\
\text { espiral, complejo, sistémico e inacabado, como el ser humano; esto indica la importancia } \\
\text { de la flexibilidad y la apertura en quien investiga, desde el momento en que 'emprende } \\
\text { su aventura' hasta cuando comunica de manera oral y escrita lo acontecido, sin embargo, } \\
\text { la claridad y solidez conceptual y el rigor del método utilizado es imprescindible. En este } \\
\text { sentido los trabajos adolecen de lo que pretenden los ítems y esto se refleja en la coherencia } \\
\text { y la cohesión de los contenidos. } \\
\text { En general, se aprecian inquietudes y búsquedas que desde el punto de vista didáctico } \\
\text { se justifican por sí mismas, dada la razón de ser del proceso enseñanza-aprendizaje y las } \\
\text { implicaciones de las acciones llevadas a cabo, encaminadas a concretar las intenciones de } \\
\text { la formación, revertidas en la configuración del tipo de seres humanos que pretendemos } \\
\text { formar. Es oportuno señalar búsquedas como la identificación de recursos y materiales, } \\
\text { la identificación de estrategias, la incorporación de otros agentes al proceso educativo; } \\
\text { sin embargo, estas acciones pueden emprenderse sin que sea condición un proceso de } \\
\text { investigación. } \\
\text { Finalmente, investigar puede ser aún, más sencillo de lo que podríamos expresar. Basta con } \\
\text { atreverse, con desequilibrarse y adentrarse en un proceso de ver distinto lo existente, de } \\
\text { interrogarse y adentrarse en la profundidad de lo desconocido con la luz de cuanto se sabe. } \\
\text { Eso sí, siempre con la exigencia de la disciplina, la fundamentación, la apertura, el rigor al } \\
\text { proceder y la sistematización del acontecer. Todo tiene comienzo. }\end{array}$ \\
\hline
\end{tabular}

